\title{
Interleukin-6 and C-reactive protein, successful aging, and mortality: the PolSenior study
}

\author{
Monika Puzianowska-Kuźnicka ${ }^{1,2^{*}}$, Magdalena Owczarz ${ }^{1,3}$, Katarzyna Wieczorowska-Tobis ${ }^{4}$, Pawel Nadrowski $^{5}$, \\ Jerzy Chudek ${ }^{6,7}$, Przemyslaw Slusarczyk ${ }^{3}$, Anna Skalska $^{8}$, Marta Jonas $^{1}$, Edward Franek ${ }^{1}$ \\ and Malgorzata Mossakowska ${ }^{3}$
}

\begin{abstract}
Background: In the elderly, chronic low-grade inflammation (inflammaging) is a risk factor for the development of aging-related diseases and frailty. Using data from several thousand Eastern Europeans aged 65 years and older, we investigated whether the serum levels of two proinflammatory factors, interleukin-6 (IL-6) and C-reactive protein (CRP), were associated with physical and cognitive performance, and could predict mortality in successfully aging elderly.

Results: IL-6 and CRP levels systematically increased in an age-dependent manner in the entire study group (IL-6: $n=3496$ individuals, $p<0.001$ and CRP: $n=3632, p=0.003$ ), and in the subgroup of successfully aging individuals who had never been diagnosed with cardiovascular disease, myocardial infarction, stroke, type 2 diabetes, or cancer, and had a Mini Mental State Examination (MMSE) score $\geq 24$ and a Katz Activities of Daily Living (ADL) score $\geq 5$ (IL-6: $n=1258$, $p<0.001$ and CRP: $n=1312, p<0.001$ ). In the subgroup of individuals suffering from aging-related diseases/disability, only IL-6 increased with age (IL-6: $n=2238, p<0.001$ and CRP: $n=2320, p=0.249)$. IL-6 and CRP levels were lower in successfully aging individuals than in the remaining study participants (both $p<0.001$ ). Higher IL-6 and CRP levels were associated with poorer physical performance (lower ADL score) and poorer cognitive performance (lower MMSE score) (both $p$ <.001). This association remained significant after adjusting for age, gender, BMI, lipids, estimated glomerular filtration rate, and smoking status. Longer survival was associated with lower concentrations of IL-6 and CRP not only in individuals with aging-related diseases/disability $(\mathrm{HR}=1.063$ per each pg/mL, $95 \% \mathrm{Cl}$ : 1.052-1.074, $p<0.001$ and $\mathrm{HR}=1.020$ per each $\mathrm{mg} / \mathrm{L}, 95 \% \mathrm{Cl}: 1.015-1.025, p<0.001$, respectively) but also in the successfully aging subgroup ( $\mathrm{HR}=1.163$ per each $\mathrm{pg} / \mathrm{mL}, 95 \% \mathrm{Cl}: 1.128-1.199, p<0.001$ and $\mathrm{HR}=1.074$ per each $\mathrm{mg} / \mathrm{L}, 95 \% \mathrm{Cl}: 1.047-1.100, p<0.001$, respectively). These associations remained significant after adjusting for age, gender, BMI, lipids and smoking status. The Kaplan-Meier survival curves showed similar results (all $p<0.001$ ).
\end{abstract}

Conclusions: Both IL- 6 and CRP levels were good predictors of physical and cognitive performance and the risk of mortality in both the entire elderly population and in successfully aging individuals.

Keywords: Aging, Successful aging, Low-grade inflammation, Inflammaging, Interleukin 6 (IL-6), High sensitivity C-reactive protein (CRP), The Mini Mental State Examination (MMSE), The Katz Activity of Daily Living (ADL), Mortality

\footnotetext{
* Correspondence: mpuzianowska@imdik.pan.pl

'Department of Human Epigenetics, Mossakowski Medical Research Centre

PAS, 5 Pawinskiego Street, 02-106 Warsaw, Poland

${ }^{2}$ Department of Geriatrics and Gerontology, Medical Centre of Postgraduate

Education, 01-826 Warsaw, Poland

Full list of author information is available at the end of the article
} 


\section{Background}

Immunosenescence is an integral part of human aging that results in a decrease in the number of naive $T$ and $B$ lymphocytes, the accumulation of memory and effector $\mathrm{T}$ and $\mathrm{B}$ cells, the production of defective antibodies, an increase in the production of autoantibodies, and in chronic low-grade inflammation (inflammaging) [1, 2]. Among the probable triggers of inflammaging are chronic viral infections, an aging-related increase in adiposity, dietary habits and aging-related changes in the composition of the gut microbiota [3-5]. Among its most important features are slight elevations of the concentrations of proinflammatory cytokines, chemokines, and adipokines, such as interleukin-1ß (IL-1ß), interleukin-6 (IL-6), tumor necrosis factor- $\alpha$ (TNF- $\alpha)$, and monocyte chemoattractant protein-1 (chemokine (C-C motif) ligand 2, CCL2) [6-8]. Proinflammatory cytokines stimulate the synthesis of $\mathrm{C}$ reactive protein (CRP) in the liver, the level of which has been shown to increase in elderly individuals [9]. While clinical signs and symptoms of inflammaging are minimal or absent, this condition contributes to various molecular pathologies, leading to vascular damage and insulin resistance [10-12] and, therefore, increases the risk of developing type 2 diabetes, cardiovascular disease, stroke, cancer, sarcopenia, neurodegeneration, and frailty [13-22]. Furthermore, low-grade inflammation predicts mortality in elderly individuals who are affected by various pathologies [15, 17, 23-25].

IL- 6 and CRP are among the most commonly used indicators of inflammation. However, while some published data suggest their causal or predictive roles in morbidity or mortality in the elderly, other studies do not support such views [26-29]. Moreover, the literature on the effects of inflammaging on mortality in successfully aging individuals is not extensive. Therefore, the main objective of the present work was to investigate whether the results of a single measurement of IL-6 and CRP levels were associated with mortality in elderly participants of the PolSenior study who were followed for an average of 4.3 years, with a particular emphasis on individuals who had never been diagnosed with aging-related diseases and remained in good physical and cognitive health. Another aim of this study was to determine possible associations between the concentrations of these factors and cognitive and physical functioning, which were assessed at the same time. Finally, we evaluated whether low-dose acetylsalicylic acid, which is frequently prescribed to seniors for the prevention of cardiovascular disease, affects IL-6 and CRP concentrations.

\section{Methods}

\section{Material}

The study group consisted of $\geq 65$ year old seniors $(n=$ 4979 individuals) who participated in the PolSenior study. The participants were randomly recruited in bundles in a stratified, proportional draw. The response rate was $42.6 \%$. The recruitment details are described elsewhere [30]. The respondents belonged to similarlysized age groups $(65-69,70-74,75-79,80-84,85-89$ and $\geq 90$ years old), each containing a similar number of males and females. A detailed questionnaire was used to obtain medical histories, current health status, socioeconomic status, demographic status, and lifestyle habits for all of the study participants. The participants also underwent a detailed examination, including elements of comprehensive geriatric assessment [30]. Individuals who had never been diagnosed with cardiovascular disease, myocardial infarction, stroke, type 2 diabetes, or cancer, and had a Mini Mental State Examination (MMSE) score $\geq 24$ and Katz Activities of Daily Living (ADL) score $\geq 5$ were classified as successfully aging. Of the entire group, blood samples were provided by 4101 individuals. Blood collection, surveys, and physical examinations were performed either on the same day or within a few days of each other. The survival of the study subjects was taken from the Population Register. This database was accessed in 2015, indicating that 1734 PolSenior participants (1318 of those who donated blood) had died. The total number of person-years of observation was 14,535.

The PolSenior project was approved by the Bioethics Commission of the Medical University of Silesia in Katowice. Each participant gave written, informed consent to participate in the study.

\section{Blood analysis}

Venous blood was collected using a vacuum system and delivered in a cooler to local laboratories within $2 \mathrm{~h}$, where serum and plasma samples were separated and frozen. All samples were then delivered to the Department of Human Epigenetics, Mossakowski Medical Research Centre in Warsaw. All of the IL-6 and CRP measurements were performed in the same laboratory. Interleukin-6 levels were measured in serum using ELISA (R\&D System, Minneapolis, MN, USA, sensitivity $0.04 \mathrm{pg} / \mathrm{mL}$ ) in 3895 individuals and CRP (high sensitivity CRP) levels were measured using a high-sensitivity immunoturbidymetric method (Modular PPE, Roche Diagnostics GmBH, Mannheim, Germany, sensitivity $0.11 \mathrm{mg} / \mathrm{L}$ ) in 4093 individuals. In the other PolSenior participants, these measurements were not performed mostly because of refusal to provide blood or because an insufficient amount of serum was collected. Other biochemical parameters were assessed using routine techniques [30]. Study subjects with leukocyte counts $>10,000 / \mu \mathrm{L}$ (indicating a considerable risk of ongoing infection) and/or who were being treated with glucocorticoids were excluded from further analyses. Therefore, analyses of IL-6 were performed in 3496 subjects, and of CRP were performed in 3632 subjects. In some of the study subjects, only IL- 6 or only CRP 
was measured. The results were presented as median $\left[1^{\text {st }}\right.$ quartile, $3^{\text {rd }}$ quartile $]$ values.

\section{Mini mental state examination and activities of daily living}

Cognitive function was assessed using the MMSE [31] which was translated into Polish. The study participants were divided into five groups: normal cognition (MMSE score 28-30), minimal cognitive impairment (MMSE score 24-27), mild (MMSE score 20-23), moderate (MMSE score 10-19), or severe (MMSE score <10) cognitive impairment [32].

Physical performance was assessed using the ADL scale [33]. Based on the six domains of the ADL (transferring, feeding, bathing, dressing, personal hygiene and grooming, toileting), the study participants were divided into independent (ADL score 5-6), partially dependent (ADL score 3-4) and totally dependent (ADL score 0-2) [34].

\section{Statistical analysis}

The statistical analyses were performed using Statistica 10 software (Statsoft Inc., Tulsa, OK, USA) and R software ( $\mathrm{R}$ Foundation for Statistical Computing, Vienna, Austria) programs. Because of the skewed distribution of the IL- 6 and CRP values, the variables were presented as median $\left[1^{\text {st }}\right.$ quartile, $3^{\text {rd }}$ quartile] values. Before the analyses, the IL- 6 and CRP values were log-transformed. The significance of associations between the analyzed factors was tested using analysis of variance (ANOVA), and analysis of co-variance (ANCOVA) for multifactorial analyses. Pearson's $r$ was used as a measure of correlations between IL- 6 and CRP levels.

A Kaplan-Meier plots were used to present survival curves, which were compared using the log-rank test. The Cox proportional hazards model was used for univariate survival analyses. In the multivariate survival analyses, age and body mass index (BMI) did not meet the assumption of proportional hazards. Therefore, the Cox proportional hazards model with time-dependent covariates was used. The hazard ratio (HR) of death and the $95 \%$ confidence interval $(\mathrm{CI})$ were calculated for associations between the analyzed variables and survival time.

For all of the statistical analyses, the level of significance was established at 0.05 .

\section{Results}

\section{Aging-associated changes in serum IL- 6 and CRP levels}

The mean age of all the study participants who met the inclusion criteria (3750 individuals, $47.8 \%$ women, $52.2 \%$ men) was $78.9 \pm 8.6$ years. The mean age of the successfully aging subgroup (35.4\% of the study population; $47.4 \%$ women, $52.6 \%$ men) was $76.3 \pm 7.9$ years, while in the remaining study participants who did not meet our definition of successful aging (64.6\% of the study population;
$48 \%$ women, $52 \%$ men) was $80.3 \pm 8.6$ years. The age difference between the successfully aging participants and the remaining study participants was significant $(p<0.001)$.

Low-dose acetylsalicylic acid is commonly prescribed to seniors for the prevention of cardiovascular disease. We initially determined whether this medication affects IL-6 or CRP concentrations and whether individuals who received it should be included in the analysis or analyzed separately. The comparison between individuals who were not currently treated with low-dose acetylsalicylic acid $v s$. individuals who took this medication showed that the median concentrations of IL- 6 were similar in both groups (2321 individuals, $2.3 \mathrm{pg} / \mathrm{mL}[1.5,3.8]$ vs. 1175 individuals, $2.4 \mathrm{pg} / \mathrm{mL}[1.6,3.8]$, respectively, $p=$ 0.22 ), as were the median CRP values (2410 individuals, $2.3 \mathrm{mg} / \mathrm{L}[1.1,4.8]$ vs. 1222 individuals, $2.3 \mathrm{mg} / \mathrm{L}$ $[1.1,4.7]$, respectively, $p=0.73)$. Therefore, all of the subsequent analyses were performed without considering whether the participants were treated with low-dose acetylsalicylic acid.

The median concentration of IL- 6 in the entire study group (3496 individuals) was $2.3 \mathrm{pg} / \mathrm{mL}[1.5,3.8]$. In successfully aging study participants (1258 individuals) it was $2.0 \mathrm{pg} / \mathrm{mL}[1.3,3.3]$, while in participants who suffered from aging-related diseases/disability (2238 individuals) it was $2.5 \mathrm{pg} / \mathrm{mL}[1.6,4.2]$. This difference was significant $(p<0.001)$. We also found that the older the age group, the higher was the median concentration of IL- 6 not only in the entire study group and in individuals with aging-related diseases/disability, but also in the subgroup of successfully aging individuals (all $p<0.001$, Table 1).

The median CRP concentration in the entire study group (3632 individuals) was $2.3 \mathrm{mg} / \mathrm{L}[1.1,4.7]$. The subgroups of successfully aging participants (1312 individuals) and those who did not meet the definition of successful aging (2320 individuals) had median concentrations $2.1 \mathrm{mg} / \mathrm{L}$ [1.0, 4.3] and $2.5 \mathrm{mg} / \mathrm{L}[1.1,5.1]$, respectively. This difference that was significant $(p<0.001)$. In the entire study group, we observed a significant increase in the median CRP concentration as age increased $(p=0.003)$. Notably, the median CRP concentration was higher in $\geq 80$ year old study participants than in younger age groups. In the study participants with aging-related diseases/disability, the median CRP level was not associated with age $(p=0.25)$. In the successfully aging subgroup, the median CRP levels were also higher in the older age groups, but the level of significance has not been reached $(p=0.09)$ (Table 1).

IL-6 and CRP levels were correlated with each other in the entire study group $(\mathrm{r}=0.502, p<0.001)$, the successfully aging subgroup $(r=0.538, p<0.001)$, and study participants with aging-related diseases/disability $(r=0.504, p<0.001)$. 
Table 1 IL- 6 and CRP concentrations in $\geq 65$ year-old seniors

\begin{tabular}{|c|c|c|c|c|c|c|}
\hline \multirow[t]{2}{*}{ Age (years) } & \multicolumn{2}{|l|}{$\mathrm{All}^{\mathrm{a}}$} & \multicolumn{2}{|c|}{ Successfully aging ${ }^{b}$} & \multicolumn{2}{|c|}{ Others $^{c}$} \\
\hline & $\bar{n}$ & Concentration $^{d}$ & $\bar{n}$ & Concentration $^{d}$ & $\bar{n}$ & Concentration $^{\circ}$ \\
\hline & \multicolumn{6}{|c|}{ IL-6 [pg/mL] } \\
\hline $65-69$ & 588 & $1.8[1.2,2.9]$ & 296 & $1.8[1.1,3.0]$ & 292 & $1.9[1.3,2.9]$ \\
\hline $70-74$ & 681 & $1.9[1.3,3.1]$ & 308 & $1.7[1.1,2.8]$ & 373 & $2.2[1.4,3.3]$ \\
\hline $75-79$ & 596 & $2.1[1.4,3.4]$ & 231 & $1.9[1.3,2.8]$ & 365 & $2.4[1.6,3.6]$ \\
\hline $80-84$ & 557 & $2.5[1.7,3.7]$ & 163 & $2.4[1.5,3.5]$ & 394 & $2.5[1.7,3.8]$ \\
\hline $85-89$ & 598 & $2.8[1.8,4.9]$ & 173 & $2.7[1.8,4.3]$ & 425 & $2.8[1.8,5.1]$ \\
\hline \multirow[t]{2}{*}{$90+$} & 476 & $3.5[2.1,5.5]$ & 87 & $3.3[2.3,5.1]$ & 389 & $3.5[2.1,5.6]$ \\
\hline & \multicolumn{6}{|c|}{ CRP $[\mathrm{mg} / \mathrm{L}]$} \\
\hline $65-69$ & 614 & $2.2[1.1,4.6]$ & 311 & $2.0[1.0,4.1]$ & 303 & $2.6[1.2,5.5]$ \\
\hline $70-74$ & 706 & $2.1[1.1,4.1]$ & 321 & $1.9[1.0,3.9]$ & 385 & $2.2[1.1,4.4]$ \\
\hline $75-79$ & 627 & $2.2[1.1,4.4]$ & 245 & $1.9[1.0,3.8]$ & 382 & $2.6[1.2,4.8]$ \\
\hline $80-84$ & 572 & $2.4[1.1,5.2]$ & 169 & $2.4[1.0,5.3]$ & 403 & $2.3[1.1,5.2]$ \\
\hline $85-89$ & 621 & $2.5[1.1,5.1]$ & 177 & $2.8[1.2,4.6]$ & 444 & $2.4[1.1,5.2]$ \\
\hline $90+$ & 492 & $2.7[1.1,5.5]$ & 89 & $2.6[1.3,5.3]$ & 403 & $2.7[1.1,5.7]$ \\
\hline
\end{tabular}

a: Excluded are individuals with leukocytosis exceeding $10,000 / \mu \mathrm{L}$ or treated with glucocorticoids

b: Only individuals without past or current cancer, type 2 diabetes, cardiovascular disease/myocardial infarction/stroke, and with the MMSE score $\geq 24$ and the ADL score 5-6

: Individuals who did not meet the definition of successful aging

d: Concentrations of IL-6 and CRP are shown as median [1 ${ }^{\text {st }}$ quartile, $3^{\text {rd }}$ quartile]

$n$ number of individuals

We also evaluated whether IL- 6 and CRP concentrations differed in women and men and found that the median IL-6 concentrations were higher in men (1673 women, $2.2 \mathrm{pg} / \mathrm{mL}[1.5,3.6]$ vs. $1823 \mathrm{men}, 2.4 \mathrm{pg} / \mathrm{mL}[1.6,4.0]$, $p=0.006)$, whereas the median CRP concentrations were not significantly different (1735 women, $2.4 \mathrm{mg} / \mathrm{L}$ [1.2, 4.7] vs. $1897 \mathrm{men}, 2.2 \mathrm{mg} / \mathrm{L}[1.0,4.9], p=0.25)$.

\section{Association between the IL- 6 and CRP levels and other biochemical parameters and functional and cognitive performance}

IL-6 concentrations were significantly associated with BMI $(p<0.001$ for the entire study group, $p=0.015$ for the successfully aging subgroup, and $p=0.007$ for study participants with aging-related diseases/disability). Notably, in individuals with a BMI $<18.5 \mathrm{~kg} / \mathrm{m}^{2}$, the median IL-6 value was the highest, while in overweight individuals it was the lowest, and again increased in the obese. In addition, the median IL- 6 value was associated with estimated glomerular filtration rate (eGFR) $(p<0.001$ for the entire study group, $p<0.001$ for the successfully aging subgroup, and $p<0.001$ for study participants with aging-related diseases/disability) and was the highest in individuals with the lowest eGFR, as well as with heart rate $(p<0.001, p<0.001$ and $p<0.001)$ where it was the highest in individuals with a heart rate $>80 / \mathrm{min}$. It was also associated with smoking status $(p=0.02$ for the entire study group and $p=0.016$ for participants with agingrelated diseases/disability); it was the highest in current smokers. No association with smoking status was found in the successfully aging subgroup. Of note, the IL- 6 concentration was negatively associated with total cholesterol levels $(p<0.001$ for the entire study group, $p<0.001$ for the successfully aging subgroup, and $p<0.001$ for study participants with aging-related diseases/disability), LDL cholesterol $(p<0.001, p=0.007$ and $p<0.001)$, and HDL cholesterol $(p<0.001, p<0.001$ and $p<0.001)$ (Table 2). The multifactorial analysis including age, gender, BMI, HDL, LDL, eGFR and smoking status, showed that only gender lost its significant association with IL-6 in the entire study group. In the successfully aging subgroup, gender and LDL lost their associations with IL-6, while in participants with aging-related diseases/disability the association was lost for gender and eGFR. The other factors remained significantly associated with IL-6.

We also evaluated whether IL-6 concentrations were related to functional and cognitive performance. We found that higher IL-6 levels were associated with poorer physical performance (lower ADL score) and poorer cognitive performance (lower MMSE score) (all $p<0.001$ for the entire study group as well as for both subgroups) (Table 2). He multifactorial analyses that were adjusted for age, gender, BMI, HDL, LDL, eGFR and smoking status revealed that ADL and MMSE scores in the entire studied group remained associated with IL-6 $(p=0.006$ and $p=0.007$, respectively). Such an analysis was not performed separately in the successfully aging subgroup because only individuals with the highest ADL and MMSE scores, 
Table 2 IL-6 and CRP concentration in $\geq 65$ year-old seniors in relation to select clinical and biochemical parameters, and functional status

\begin{tabular}{|c|c|c|c|c|c|c|c|c|c|c|c|c|c|}
\hline & & \multicolumn{6}{|c|}{ IL-6 [pg/mL] } & \multicolumn{6}{|c|}{ CRP $[\mathrm{mg} / \mathrm{L}]$} \\
\hline & & \multicolumn{2}{|l|}{$\bar{A} \|^{a}$} & \multicolumn{2}{|c|}{ Successfully aging ${ }^{b}$} & \multicolumn{2}{|c|}{ Others $^{c}$} & \multicolumn{2}{|l|}{$\overline{A l^{a}}$} & \multicolumn{2}{|c|}{ Successfully aging ${ }^{b}$} & \multicolumn{2}{|c|}{ Others $^{c}$} \\
\hline & & $\bar{n}$ & Concentration $^{d}$ & $\bar{n}$ & Concentration $^{d}$ & $\bar{n}$ & Concentration $^{d}$ & $\bar{n}$ & Concentration $^{\mathrm{d}}$ & $\bar{n}$ & Concentration $^{\mathrm{d}}$ & $\bar{n}$ & Concentration $^{\mathrm{d}}$ \\
\hline \multirow[t]{5}{*}{ BMI $\left[\mathrm{kg} / \mathrm{m}^{2}\right]$} & $<18.5$ & 60 & $3.2[1.8,5.4]$ & 21 & $3.2[1.7,4.8]$ & 39 & $3.2[1.9,5.7]$ & 64 & $2.3[1.0,7.4]$ & 21 & $1.8[0.7,7.5]$ & 43 & $2.5[1.0,7.2]$ \\
\hline & $18.5-24.9$ & 814 & $2.3[1.4,3.9]$ & 315 & $1.9[1.2,3.2]$ & 499 & $2.5[1.6,4.5]$ & 865 & $1.7[0.8,3.8]$ & 336 & $1.5[0.8,3.0]$ & 529 & $1.8[0.9,4.3]$ \\
\hline & $25-29.9$ & 1381 & $2.2[1.4,3.5]$ & 548 & $1.9[1.3,3.2]$ & 833 & $2.3[1.5,3.8]$ & 1425 & $2.1[1.0,4.2]$ & 569 & $2.0[1.0,4.0]$ & 856 & $2.2[1.0,4.3]$ \\
\hline & $30-39.9$ & 997 & $2.3[1.6,3.6]$ & 343 & $2.2[1.4,3.6]$ & 654 & $2.4[1.7,3.6]$ & 1025 & $2.8[1.5,5.2]$ & 354 & $2.9[1.6,5.4]$ & 671 & $2.7[1.4,5.1]$ \\
\hline & $\geq 40$ & 69 & $2.8[2.1,4.1]$ & 17 & $2.5[1.9,3.4]$ & 52 & $2.9[2.1,4.9]$ & 69 & $4.2[2.2,8.8]$ & 17 & $4.3[2.5,7.8]$ & 52 & $4.1[2.1,9.1]$ \\
\hline \multirow[t]{5}{*}{ Cholesterol [mg/dL] } & $<175$ & 1029 & $2.7[1.7,4.8]$ & 256 & $2.4[1.5,4.4]$ & 773 & $2.8[1.8,5.1]$ & 1085 & $2.3[1.0,5.3]$ & 267 & $2.2[1.0,5.0]$ & 818 & $2.4[1.0,5.3]$ \\
\hline & 175-189 & 452 & $2.3[1.6,3.8]$ & 178 & $2.2[1.4,3.7]$ & 274 & $2.4[1.7,3.8]$ & 478 & $2.4[1.1,5.1]$ & 184 & $1.9[1.0,4.2]$ & 294 & $2.6[1.1,5.7]$ \\
\hline & 190-239 & 1302 & $2.2[1.5,3.5]$ & 512 & $2.0[1.3,3.1]$ & 790 & $2.4[1.6,3.8]$ & 1375 & $2.2[1.1,4.4]$ & 543 & $2.2[1.0,4.1]$ & 832 & $2.3[1.1,4.7]$ \\
\hline & 240-309 & 593 & $2.0[1.4,3.1]$ & 275 & $1.8[1.2,2.7]$ & 318 & $2.2[1.5,3.4]$ & 627 & $2.3[1.2,4.5]$ & 291 & $2.1[1.2,4.0]$ & 336 & $2.7[1.4,5.2]$ \\
\hline & $\geq 310$ & 65 & $2.2[1.4,3.6]$ & 27 & $2.4[1.4,3.7]$ & 38 & $2.2[1.5,3.6]$ & 67 & $3.3[1.5,5.2]$ & 27 & $2.1[1.0,5.0]$ & 40 & $3.6[1.7,5.3]$ \\
\hline \multirow[t]{5}{*}{$\mathrm{HDL}[\mathrm{mg} / \mathrm{dL}]$} & $<40$ & 774 & $3.0[1.8,4.9]$ & 199 & $2.7[1.6,3.9]$ & 575 & $3.1[1.9,5.3]$ & 822 & $2.9[1.4,6.2]$ & 211 & $2.6[1.3,5.4]$ & 611 & $3.0[1.5,6.5]$ \\
\hline & $40-44$ & 525 & $2.6[1.7,4.4]$ & 168 & $2.4[1.6,4.0]$ & 357 & $2.7[1.8,4.5]$ & 549 & $2.4[1.2,5.0]$ & 176 & $2.3[1.3,4.7]$ & 373 & $2.4[1.2,5.1]$ \\
\hline & $45-49$ & 528 & $2.4[1.6,4.0]$ & 190 & $2.1[1.3,3.5]$ & 338 & $2.6[1.8,4.2]$ & 549 & $2.5[1.1,5.3]$ & 201 & $2.5[1.1,4.8]$ & 348 & $2.4[1.2,5.9]$ \\
\hline & $50-59$ & 851 & $2.1[1.4,3.4]$ & 362 & $1.9[1.3,3.2]$ & 489 & $2.2[1.5,3.4]$ & 900 & $2.2[1.1,4.2]$ & 370 & $2.1[1.0,3.9]$ & 530 & $2.3[1.1,4.3]$ \\
\hline & $\geq 60$ & 760 & $1.8[1.2,3.0]$ & 328 & $1.7[1.1,2.6]$ & 432 & $2.0[1.3,3.3]$ & 810 & $1.8[0.8,3.6]$ & 353 & $1.6[0.8,3.1]$ & 457 & $1.9[0.9,4.1]$ \\
\hline \multirow[t]{6}{*}{ LDL [mg/dL] } & $<70$ & 329 & $2.8[1.8,5.1]$ & 53 & $2.2[1.6,3.6]$ & 276 & $2.9[1.9,5.5]$ & 347 & $2.4[0.9,4.9]$ & 55 & $2.4[0.7,5.0]$ & 292 & $2.4[1.0,4.9]$ \\
\hline & $71-99$ & 809 & $2.5[1.6,4.2]$ & 234 & $2.2[1.5,4.1]$ & 575 & $2.6[1.6,4.2]$ & 860 & $2.3[1.0,4.7]$ & 249 & $1.9[1.0,4.3]$ & 611 & $2.4[1.0,5.0]$ \\
\hline & $100-114$ & 506 & $2.3[1.6,4.0]$ & 204 & $2.1[1.3,3.6]$ & 302 & $2.5[1.7,4.3]$ & 530 & $2.1[1.0,4.8]$ & 214 & $2.1[1.0,4.2]$ & 316 & $2.1[1.0,5.1]$ \\
\hline & $115-154$ & 1168 & $2.2[1.4,3.5]$ & 463 & $1.9[1.3,3.1]$ & 705 & $2.4[1.6,3.7]$ & 1234 & $2.2[1.1,4.6]$ & 485 & $2.1[1.0,4.0]$ & 749 & $2.5[1.2,5.1]$ \\
\hline & 155-189 & 468 & $2.1[1.5,3.3]$ & 218 & $1.9[1.3,2.9]$ & 250 & $2.2[1.6,3.8]$ & 494 & $2.5[1.4,4.6]$ & 230 & $2.3[1.2,4.1]$ & 264 & $2.7[1.5,5.5]$ \\
\hline & $\geq 190$ & 159 & $2.1[1.3,3.2]$ & 75 & $1.8[1.2,3.0]$ & 84 & $2.2[1.5,3.4]$ & 166 & $2.7[1.2,5.4]$ & 78 & $2.3[1.2,5.4]$ & 88 & $3.0[1.3,5.4]$ \\
\hline \multirow[t]{3}{*}{ Glucose $[\mathrm{mg} / \mathrm{dL}]$} & $<100$ & 2133 & $2.3[1.5,3.8]$ & 924 & $2.0[1.3,3.3]$ & 1209 & $2.5[1.7,4.4]$ & 2261 & $2.2[1.0,4.6]$ & 966 & $2.1[1.0,4.1]$ & 1295 & $2.4[1.1,5.0]$ \\
\hline & 100-139.9 & 1042 & $2.4[1.6,3.7]$ & 324 & $2.1[1.4,3.4]$ & 718 & $2.5[1.6,3.8]$ & 1089 & $2.3[1.1,4.8]$ & 346 & $2.2[1.1,4.8]$ & 743 & $2.4[1.1,4.9]$ \\
\hline & $\geq 140$ & 256 & $2.5[1.7,4.1]$ & na & na & 256 & $2.5[1.7,4.1]$ & 272 & $3.0[1.4,6.8]$ & na & na & 272 & $3.0[1.4,6.8]$ \\
\hline \multirow[t]{3}{*}{ eGFR $\left[\mathrm{mL} / \mathrm{min} / 1.73 \mathrm{~m}^{2}\right]$} & $<45$ & 359 & $3.2[2.1,5.3]$ & 70 & $3.8[2.6,6.7]$ & 289 & $3.0[2.0,5.2]$ & 378 & $3.2[1.5,6.3]$ & 77 & $3.5[1.9,6.3]$ & 301 & $3.0[1.5,6.3]$ \\
\hline & $45-60$ & 639 & $2.7[1.7,4.1]$ & 187 & $2.4[1.5,3.6]$ & 452 & $2.8[1.8,4.5]$ & 668 & $2.5[1.1,5.4]$ & 192 & $2.2[1.1,4.4]$ & 476 & $2.7[1.2,6.2]$ \\
\hline & $>60$ & 2421 & $2.1[1.4,3.5]$ & 977 & $1.9[1.3,3.1]$ & 1444 & $2.3[1.6,3.8]$ & 2531 & $2.2[1.0,4.4]$ & 1019 & $2.0[1.0,4.1]$ & 1512 & $2.3[1.0,4.7]$ \\
\hline \multirow[t]{3}{*}{ Heart rate [per min] } & $<60$ & 341 & $2.2[1.5,3.6]$ & 126 & $1.8[1.2,2.9]$ & 215 & $2.6[1.6,4.0]$ & 354 & $1.6[0.9,3.6]$ & 131 & $1.8[1.0,3.6]$ & 223 & $1.5[0.9,3.6]$ \\
\hline & $60-80$ & 2374 & $2.2[1.5,3.6]$ & 893 & $2.0[1.3,3.2]$ & 1481 & $2.3[1.6,3.8]$ & 2463 & $2.3[1.0,4.5]$ & 929 & $2.1[1.0,4.0]$ & 1534 & $2.4[1.1,4.9]$ \\
\hline & $>80$ & 768 & $2.7[1.7,4.8]$ & 239 & $2.4[1.5,4.0]$ & 529 & $2.8[1.8,5.1]$ & 801 & $3.0[1.4,6.2]$ & 252 & $2.7[1.3,5.6]$ & 549 & $3.1[1.4,6.3]$ \\
\hline Smoking & Never & 1968 & $2.3[1.5,3.7]$ & 689 & $1.9[1.3,3.1]$ & 1279 & $2.4[1.6,4.1]$ & 2035 & $2.3[1.1,4.5]$ & 710 & $2.1[1.0,3.9]$ & 1325 & $2.4[1.1,4.9]$ \\
\hline
\end{tabular}


Table 2 IL-6 and CRP concentration in $\geq 65$ year-old seniors in relation to select clinical and biochemical parameters, and functional status (Continued)

\begin{tabular}{|c|c|c|c|c|c|c|c|c|c|c|c|c|c|}
\hline & Past & 1196 & $2.4[1.5,3.8]$ & 424 & $2.0[1.4,3.3]$ & 772 & $2.5[1.6,4.0]$ & 1250 & $2.2[1.0,4.8]$ & 450 & $2.1[1.0,4.5]$ & 800 & $2.3[1.0,5.0]$ \\
\hline & Current & 304 & $2.7[1.7,4.5]$ & 140 & $2.4[1.4,3.7]$ & 164 & $3.0[1.8,5.2]$ & 319 & $3.1[1.3,6.2]$ & 147 & $2.4[1.1,5.1]$ & 172 & $3.4[1.5,7.7]$ \\
\hline \multirow[t]{5}{*}{ MMSE [points] } & $28-30$ & 1121 & $1.9[1.3,3.1]$ & 606 & $1.9[1.2,3.0]$ & 515 & $2.0[1.4,3.1]$ & 1153 & $2.0[1.0,4.1]$ & 629 & $1.9[1.0,4.1]$ & 524 & $2.1[1.0,4.1]$ \\
\hline & $24-27$ & 1245 & $2.3[1.5,3.7]$ & 637 & $2.2[1.4,3.6]$ & 608 & $2.4[1.6,4.0]$ & 1302 & $2.3[1.1,4.6]$ & 668 & $2.3[1.1,4.4]$ & 634 & $2.5[1.1,5.1]$ \\
\hline & $20-23$ & 593 & $2.6[1.7,4.3]$ & na & na & 593 & $2.6[1.7,4.3]$ & 617 & $2.4[1.2,5.2]$ & na & na & 617 & $2.4[1.2,5.2]$ \\
\hline & $10-19$ & 324 & $3.0[2.0,5.5]$ & na & na & 324 & $3.0[2.0,5.5]$ & 348 & $2.5[1.0,5.4]$ & na & na & 348 & $2.5[1.0,5.4]$ \\
\hline & $<10$ & 111 & $3.3[2.1,6.0]$ & na & na & 111 & $3.3[2.1,6.0]$ & 114 & $3.7[1.5,8.3]$ & na & na & 114 & $3.7[1.5,8.3]$ \\
\hline \multirow[t]{3}{*}{ ADL [points] } & $5-6$ & 3112 & $2.2[1.5,3.6]$ & 1258 & $2.0[1.3,3.3]$ & 1854 & $2.3[1.6,3.7]$ & 3220 & $2.2[1.0,4.4]$ & 1312 & $2.1[1.0,4.3]$ & 1908 & $2.2[1.0,4.5]$ \\
\hline & $3-4$ & 205 & $3.2[2.2,6.2]$ & na & na & 205 & $3.2[2.2,6.2]$ & 220 & $3.4[1.7,9.3]$ & na & na & 220 & $3.4[1.7,9.3]$ \\
\hline & $0-2$ & 165 & $4.2[2.6,7.4]$ & na & na & 165 & $4.2[2.6,7.4]$ & 178 & $3.9[1.9,9.4]$ & na & na & 178 & $3.9[1.9,9.4]$ \\
\hline
\end{tabular}

a: Excluded are individuals with leukocytosis exceeding $10,000 / \mathrm{mm}^{3}$ or treated with glucocorticoids

b: Only individuals without past or current cancer, type 2 diabetes, cardiovascular disease/myocardial infarction/stroke, and with the MMSE score $\geq 24$ and the ADL score 5-6

: Individuals who did not meet the definition of successful aging

: Concentrations of IL-6 and CRP are shown as median [ $1^{\text {st }}$ quartile, $3^{\text {rd }}$ quartile]

$n$ Number of individuals

na Not applicable 
reflecting good physical and cognitive performance, were included in this subgroup.

The CRP concentration was significantly associated with BMI $(p<0.001$ for the entire study group, $p<0.001$ for the successfully aging subgroup, and $p<0.001$ for study participants with aging-related diseases/disability). The CRP concentration was the lowest in the group of normal-weight individuals and then systematically increased as BMI increased. Notably, it was also higher in individuals with a $\mathrm{BMI}<18.5 \mathrm{~kg} / \mathrm{m}^{2}$ compared with normal-weight study subjects. Additionally, the CRP concentration was associated with fasting glucose in the entire study group $(p=0.003)$ and individuals with aging-related diseases/disability $(p=0.006)$ and was the highest in individuals with a glucose level $\geq 140 \mathrm{mg} / \mathrm{dL}$. Notably, in the successfully aging subgroup no association was found. The CRP concentration was also associated with eGFR ( $p<0.001$ for the entire study group, $p<0.001$ for the successfully aging subgroup, and $p<0.001$ for participants with aging-related diseases/disability) and was the highest in individuals with the lowest eGFR, as well as with heart rate $(p<0.001, p<0.001$ and $p<0.001)$ where it was the highest in individuals with a heart rate $>80 / \mathrm{min}$. Furthermore, the CRP concentration was also associated with smoking status in the entire study group $(p=0.005)$ and in individuals with aging-related diseases/disability $(p=0.002)$ where it was the highest in current smokers; however, no association with smoking status was found in the successfully aging subgroup. Finally, The CRP concentration was negatively associated with the level of HDL cholesterol $(p<0.001, p<0.001$ and $p<0.001)$ (Table 2). The multifactorial analysis including age, gender, BMI, HDL, eGFR and smoking status revealed that all of the factors remained significantly associated with CRP in the entire study group and successfully aging subgroup, whereas age lost its significant association in the subgroup of participants with aging-related diseases/disability.

We also found that higher CRP levels were associated with poorer physical performance (lower ADL score) and poorer cognitive performance (lower MMSE score) (all $p<0.001$ for the entire study group as well as for both subgroups, Table 2). The multifactorial analyses that were adjusted for age, gender, BMI, HDL, eGFR and smoking status revealed that in the entire studied group the ADL and MMSE scores remained related to CRP at statistically significant level $(p=0.019$ and $p<0.001$ respectively). We did not perform such an analysis in the successfully aging subgroup because only individuals with the highest ADL and MMSE scores were included in this subgroup.

\section{Association between IL- 6 and CRP levels and survival}

The 1-year mortality rate was $6.6 \%, 2.6 \%$, and $8.8 \%$ for the entire study group, the successfully aging subgroup, and study participants with aging-related diseases/disability, respectively. In the univariate analysis, longer survival was associated with a lower IL-6 concentration: HR = 1.077 per each pg/mL (95 \% CI: $1.068-1.086, p<0.001)$ in the entire study group, $\mathrm{HR}=1.163$ per each $\mathrm{pg} / \mathrm{mL}(95 \%$ CI: $1.128-1.199, p<0.001)$ in the successfully aging subgroup, and $\mathrm{HR}=1.063$ per each $\mathrm{pg} / \mathrm{mL}$ (95 \% CI: 1.052 $1.074, p<0.001)$ in individuals with aging-related diseases/ disability. Longer survival was also associated with a lower CRP concentration: $\mathrm{HR}=1.025$ per each $\mathrm{mg} / \mathrm{L}$ (95\% CI: $1.020-1.029, p<0.001)$ in the entire study group, $\mathrm{HR}=$ 1.074 per each mg/L (95 \% CI: $1.047-1.100, p<0.001$ ) in successfully aging study participants, and $\mathrm{HR}=1.020$ per each $\mathrm{pg} / \mathrm{mL}(95 \%$ CI: $1.015-1.025, p<0.001)$ in the remaining participants.

The results of the univariate analysis were consistent with the Kaplan-Meier survival curves, in which higher concentrations of IL- 6 and CRP were associated with a lower probability of survival in the entire group of seniors, in successfully aging ones, as well as in individuals with aging-related diseases/disability (all $p<0.001$ ) (Figs. 1, 2).

A statistical model was applied that included IL-6 value, gender, age, BMI, HDL, LDL, eGFR and smoking status. We found that longer survival was associated with a lower IL-6 concentration, even after adjusting for these covariates, in the entire study group: $\mathrm{HR}=1.042$ per each $\mathrm{pg} / \mathrm{mL}$ (95\% CI: $1.029-1.055, p<0.001$ ), the successfully aging subgroup: $\mathrm{HR}=1.112$ per each $\mathrm{pg} / \mathrm{mL}$ (95 \% CI: 1.069-1.155, $p<0.001$ ), as well as in study participants with aging-related diseases/disability: $\mathrm{HR}=$ 1.031 per each $\mathrm{pg} / \mathrm{mL}$ (95 \% CI: $1.018-1.045, p<0.001)$.

We also tested a model that included CRP value, gender, age, BMI, HDL, eGFR and smoking status, and found that longer survival was associated with a lower CRP concentration after adjusting for these factors in the entire group of seniors: $\mathrm{HR}=1.017$ per each $\mathrm{mg} / \mathrm{L}(95 \% \mathrm{CI}: 1.012-1.023$, $p<0.001)$, in the successfully aging subgroup: $\mathrm{HR}=1.035$ per each $\mathrm{mg} / \mathrm{L}$ (95 \% CI: 1.021-1.050, $p<0.001$ ), and in the remaining study participants with aging-related diseases/disability: $\mathrm{HR}=1.013$ per each $\mathrm{pg} / \mathrm{mL}$ (95\% CI: $1.007-1.019, p<0.001)$.

\section{Discussion}

It is well documented that chronic inflammation is associated with aging-related morbidity [13-22], and with mortality in affected individuals $[15,17,23-25]$. Therefore, the present study evaluated a large group of Eastern European Caucasian seniors to determine whether results of a single measurement of the levels of two proinflammatory factors, IL-6 and CRP, were associated with biochemical and functional parameters and whether they were predictors of mortality. We performed this analysis for the entire study group of $\geq 65$ year-old seniors who were not preselected on the basis of their health and functional status, as 

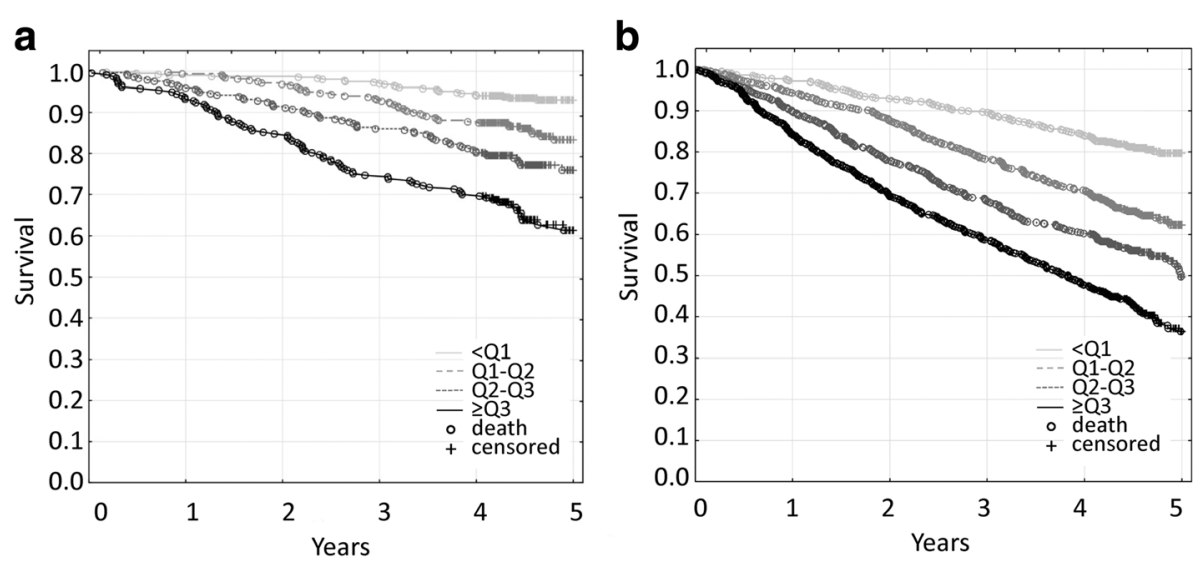

Fig. 1 Kaplan-Meier survival curves for the elderly population that was classified according to quartiles of IL-6 concentrations. a. In the successfully aging subgroup, the 1 -year mortality rates were $1.0 \%$ for the $<1^{\text {st }}$ quartile, $0.6 \%$ for the $1^{\text {st }}-2^{\text {nd }}$ quartile, $4.1 \%$ for the $2^{\text {nd }}-3^{\text {rd }}$ quartile, and $6.8 \%$ for the $>3^{\text {rd }}$ quartile. The differences between the $<1^{\text {st }}$ quartile and all of the other quartiles were significant (all $p<0.001$ ). $\mathbf{b}$. In the subgroup of individuals who suffered from aging-related diseases/disability, the 1 -year mortality rates were $2.9 \%$ for the $<1^{\text {st }}$ quartile, $5.7 \%$ for the $1^{\text {st }}-2^{\text {nd }}$ quartile, $10.0 \%$ for the $2^{\text {nd }}-3^{\text {rd }}$ quartile, and $15.8 \%$ for the $>3^{\text {rd }}$ quartile. The differences between the $<1^{\text {st }}$ quartile and all of the other quartiles were significant (all $p<0.001$ )

well as for subgroups of successfully aging individuals and individuals with aging-related chronic diseases/disability.

There is no single generally agreed upon definition of successful aging. It is usually defined as survival to an older age while being free of aging-associated diseases, such as cardiovascular disease, cancer, neurodegeneration, and type 2 diabetes, with good physical and cognitive functioning [35]. This "biological" definition is sometimes augmented by a requirement to have good social functioning and high life satisfaction [35]. However, for the purpose of this study, in which we analyzed biological factors associated with aging, we used the most common definition that is limited to the biology of aging. An additional reason for such limitation was that social functioning and life satisfaction might be significantly influenced by nonbiological factors such as income, family situation, or place of residence. We found that IL-6 and CRP levels were good predictors of physical and cognitive performance and mortality not only in the entire aging study group and in individuals with aging-related diseases/disability, but also in individuals who were aging successfully.

IL-6 is known to induce the production of CRP in the liver [36]. Therefore, as expected, the levels of IL-6 and CRP were correlated in the elderly subjects in this study. However, aging-related changes in CRP did not accurately reflect changes in IL-6. Impaired liver function, which
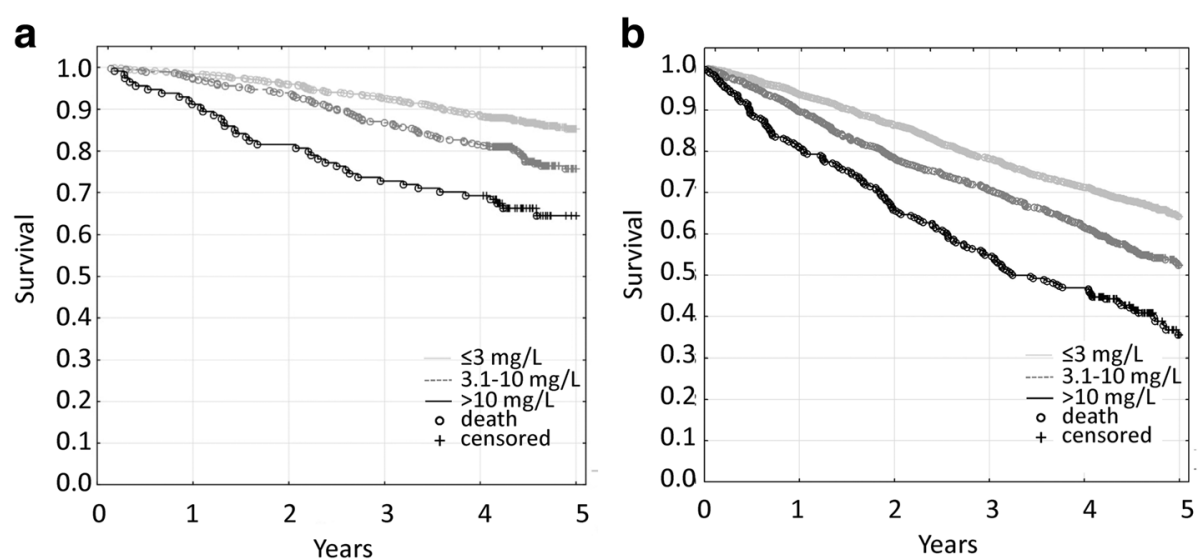

Fig. 2 Kaplan-Meier survival curves for the elderly population that was classified according to CRP concentrations. a. In the successfully aging subgroup, the 1 -year mortality rates were $1.6 \%$ for $\leq 3 \mathrm{mg} / \mathrm{L}, 2.8 \%$ for $3.1-10 \mathrm{mg} / \mathrm{L}$, and $8.8 \%$ for $>10 \mathrm{mg} / \mathrm{L}$. The differences between $\leq 3 \mathrm{mg} / \mathrm{L}$ and the other concentration ranges were significant (all $p<0.001$ ). b. In the subgroup of individuals who suffered from aging-related diseases/ disability, the 1 -year mortality rates were $6.3 \%$ for $\leq 3 \mathrm{mg} / \mathrm{L}, 10.3 \%$ for $3.1-10 \mathrm{mg} / \mathrm{L}$, and $19.2 \%$ for $>10 \mathrm{mg} / \mathrm{L}$. The differences between $\leq 3 \mathrm{mg} / \mathrm{L}$ and other concentration ranges were significant (all $p<0.001$ ) 
could be expected mainly in the subgroup of individuals who did not age successfully, might affect CRP production. We tested this hypothesis by correlating aspartate transaminase (AST) and alanine transaminase (ALT) levels with the CRP level and found that some negative correlations were significant, but all of the correlation coefficients were extremely low (data not shown). Therefore, we conclude that liver function had no significant influence on CRP production in our study group. Another plausible explanation for the lack of complete correspondence between IL6 and CRP concentrations is that CRP production is affected by other cytokines, such as IL-1 and IL-17 [36], which were not measured in the present study.

Notably, although statistically significant, the differences between mean IL- 6 and CRP concentrations in the successfully aging participants and remaining study participants who suffered form from aging-related diseases/disability were only approximately $20 \%(2 \mathrm{pg} / \mathrm{mL} v$ s. $2.5 \mathrm{pg} / \mathrm{mL}$ and $2.1 \mathrm{mg} / \mathrm{L} v s .2 .5 \mathrm{mg} / \mathrm{L}$, respectively). Therefore, the question arises as to the reason why, despite such a small differences, some individuals experienced healthy aging, while others suffered from aging-related diseases. The most likely explanation for this phenomenon is that the phenotype of aging results not only from the amount of the examined proinflammatory factors, but also from a balance between numerous proinflammatory and antiinflammatory agents (inflammaging $v$ s. anti-inflammaging) [37, 38]. Moreover, the effect of such a balance might be modified by other conditions, such as diet, body fat content, level of physical activity, smoking, and other disease risk factors, including genetic background [39-42].

Another important finding of this study was that the lowest IL-6 levels were found in normal-weight and overweight individuals, and the lowest CRP levels were found in normal-weight individuals. Such a U-shaped relationship between BMI and proinflammatory factors supports the theory of the "obesity paradox" stating that in the elderly, lower morbidity and mortality are associated with a normal body weight or being overweight [43-46], whereas being underweight or obese (especially morbidly obese) poses a high risk of mortality. Based on the present results, we speculate that this phenomenon might be, at least partially, attributable to an increase in systemic inflammation in extreme weight groups. Notably, in our study participants, a $\mathrm{BMI}<18.5 \mathrm{~kg} / \mathrm{m}^{2}$ was associated with the highest IL-6 level and, to a lesser extent, an increase in CRP level. Data that were obtained from the revised Mini Nutritional Assessment Short Form and serum biochemical parameters indicated that these individuals were undernourished and vitamin D-deficient (even though, some of them were still able to meet our phenotypic criteria for successful aging). The available data suggest that poor nutritional status and vitamin $\mathrm{D}$ deficiency might be associated with increased levels of proinflammatory factors, such as TNF- $\alpha$, IL-6, and CRP [47-49]. Therefore, in our underweight elderly patients, high levels of IL-6 and CRP might result from a cumulative action of immunoaging and undernutrition/ malnutrition.

We also found that the IL- 6 concentration was negatively associated with concentrations of total cholesterol and its high- and low-density fractions in the entire studied population and in its subgroups, while CRP was negatively associated only with HDL. Such findings indicate that low cholesterol levels in the elderly might have adverse effects, such as the increased level of IL- 6 that we detected in the present study. Our results are partially consistent with previous studies that reported the existence of similar correlations in oldest-old group of $\geq 85$ year-old individuals $[50,51]$. However, we found that such relationships were also true for seniors who were $\geq 65$ years old. Longitudinal studies indicate that aging might be associated with a decrease in total cholesterol and LDL levels and an increase in HDL levels, which is mostly a result of decreasing weight [52]. On the other hand, increased levels of proinflammatory factors are attributable to a higher body weight $[53,54]$. Therefore, an inverse relationship between lipids and proinflammatory factors in seniors might be unrelated to total adipose tissue content but may be related to the abdominal localization of adipose tissue $[55,56]$. Alternatively, adipose tissue might not be a key factor in the interplay between lipids and inflammation in older age groups.

Consistent with previous findings [23, 57], we found that higher IL-6 and CRP levels were associated with poorer cognitive and/or functional performance, as well as with a higher risk of mortality. This could be explained by the fact that aging-associated chronic inflammation is one of the major causes of aging-related diseases, that might negatively affect the aging phenotype and shorten one's lifespan [13-22]. However, we found that higher levels of IL- 6 and CRP posed an even higher risk of allcause mortality in physically and cognitively healthy, successfully aging individuals who did not suffer from major aging-related diseases, reflected by 1-year mortality rates (see Figs. 1 and 2 legends), and confirmed by 3-year mortality rates (IL-6: $2.9 \%$ for $<1^{\text {st }}$ quartile, $6.9 \%$ for $1^{\text {st }}-2^{\text {nd }}$ quartile, $14.0 \%$ for $2^{\text {nd }}-3^{\text {rd }}$ quartile and $25.3 \%$ for $>3^{\text {rd }}$ quartile of IL- 6 concentration; because there is no established "normal" IL-6 concentration range, we divided the study subjects into IL-6 concentration quartiles; CRP: $7.3 \%$ for $\leq 3 \mathrm{mg} / \mathrm{L}, 13.2 \%$ for $3.1-10 \mathrm{mg} / \mathrm{L}$, and $27.2 \%$ for $>10 \mathrm{mg} / \mathrm{L}$ ). Although these deaths could be partially attributed to newly diagnosed aging-associated diseases [21], we speculate that in the individuals who met our criteria of successful aging, elevated levels of proinflammatory factors may serve as an indicator of the increased risk of death or may actually be associated with such risk through the activation of as-yet unidentified 
pathological mechanisms other than those that lead to cardiovascular disease, diabetes, cancer, or neurodegeneration.

Finally, we found that low-dose acetylsalicylic acid, which is very commonly administered in the elderly population for prevention of cardiovascular events, did not affect IL-6 or CRP levels, which was consistent with recently published results regarding 35 to 75-year-old participants of the Swiss CoLaus Study [58]. This previous study and our present results suggest that the well-studied cardioprotective action of low-dose acetylsalicylic acid may not be attributable to the lowering of IL-6 or CRP levels but rather other mechanisms, such as the modification of other cytokine concentrations.

The strengths of this study reside in the large size of the study group, the mode of recruitment (from urban and rural municipalities), the equally-sized 5-year age cohorts, the equal representation of both sexes, and detailed baseline clinical and biochemical data that allowed us to identify the group of successfully aging individuals based on various parameters [30]. On the other hand, one limitation of the present study was that not all of the study participants had their blood drawn. However, those who did not provide blood were not preselected on the basis of any condition, and we believe that the chance of bias for this reason is relatively low. Another limitation is that the lack of data regarding morbidity after the baseline interview prevented us from determining whether or not and to what extent new cases of aging-related diseases might explain associations between IL- 6 and CRP levels and mortality in successfully aging individuals.

\section{Conclusions}

In the present study, IL-6 and CRP levels in the elderly systematically increased in an age-dependent manner in the entire study group, the successfully aging subgroup, and in individuals who suffered from aging-related diseases/disability. Higher IL-6 and CRP levels were associated with poorer cognitive and/or functional performance, and a higher risk of mortality also in successfully aging individuals. Our data support the notion that a single measurement of IL-6 and/or CRP concentrations in elderly individuals is a good predictor of physical and cognitive performance and mortality in the entire elderly population, including successfully aging individuals.

\section{Abbreviations}

$A D L$, katz activities of daily living scale; BMI, body mass index; CCL2, monocyte chemoattractant protein-1 (chemokine (C-C motif) ligand 2); CRP, C-reactive protein; eGFR, estimated glomerular filtration rate; $\mathrm{HDL}$, highdensity cholesterol; HR, hazard ratio; IL-1ß, interleukin-1ß; IL-6, interleukin-6; LDL, low-density cholesterol; MMSE, mini mental state examination; TNF-a, tumor necrosis factor-a.

\section{Acknowledgements}

This work was supported by the Polish Ministry of Science and Higher Education grant PBZ-MEiN-9/2/2006 - K143/P01/2007/1 ("PolSenior").

\section{Authors' contributions}

MPK conceived the project, analyzed and interpreted the data and wrote the paper, MO performed the experiments and analyzed the data, JC, KWT and $\mathrm{AS}$ acquired and analyzed the data and revised the manuscript, EF analyzed the data and revised the manuscript, MJ and PN acquired and analyzed the data, PS performed the statistical analysis and analyzed the data, MM participated in project development, analyzed and interpreted the data, as well as revised the manuscript. All of the authors approved the final version of the manuscript.

\section{Competing interests}

The authors declare that they have no competing interests.

\section{Author details}

'Department of Human Epigenetics, Mossakowski Medical Research Centre PAS, 5 Pawinskiego Street, 02-106 Warsaw, Poland. ²Department of Geriatrics and Gerontology, Medical Centre of Postgraduate Education, 01-826 Warsaw, Poland. ${ }^{3}$ PolSenior Project, International Institute of Molecular and Cell Biology, 02-109 Warsaw, Poland. ${ }^{4}$ Department of Palliative Medicine, Poznan University of Medical Sciences, 61-245 Poznan, Poland. ${ }^{5}$ Third Department of Cardiology, Medical University of Silesia in Katowice, 40-635 Katowice, Poland. ${ }^{6}$ Department of Pathophysiology, Faculty of Medicine, Medical University of Silesia in Katowice, 40-752 Katowice, Poland. ${ }^{7}$ Deparment of Internal Medicine and Oncological Chemotherapy, Faculty of Medicine, Medical University of Silesia in Katowice, 40-027 Katowice, Poland.

${ }^{8}$ Department of Internal Medicine and Geriatrics, Jagiellonian University Medical College, 31-351 Cracow, Poland.

Received: 12 January 2016 Accepted: 25 May 2016

Published online: 03 June 2016

\section{References}

1. Ponnappan S, Ponnappan U. Aging and immune function: molecular mechanisms to interventions. Antioxid Redox Signal. 2011;14:1551-85.

2. Cevenini $E$, Monti D, Franceschi C. Inflamm-ageing. Curr Opin Clin Nutr Metab Care. 2013;16:14-20

3. Biagi E, Nylund L, Candela M, Ostan R, Bucci L, Pini E, et al. Through ageing, and beyond: gut microbiota and inflammatory status in seniors and centenarians. PLoS One. 2010; doi: 10.1371/journal.pone.0010667.

4. Simanek AM, Dowd JB, Pawelec G, Melzer D, Dutta A, Aiello AE. Seropositivity to cytomegalovirus, inflammation, all-cause and cardiovascular disease-related mortality in the United States. PLoS One. 2011; doi:10.1371/ journal.pone.0016103.

5. Brinkley TE, Hsu FC, Beavers KM, Church TS, Goodpaster BH, Stafford RS, et al. Total and abdominal adiposity are associated with inflammation in older adults using a factor analysis approach. J Gerontol A Biol Sci Med Sci. 2012;67:1099-106.

6. Hager K, Machein U, Krieger S, Platt D, Seefried G, Bauer J. Interleukin-6 and selected plasma proteins in healthy persons of different ages. Neurobiol Aging. 1994;15:771-2.

7. Roubenoff R, Harris TB, Abad LW, Wilson PW, Dallal GE, Dinarello CA. Monocyte cytokine production in an elderly population: effect of age and inflammation. J Gerontol A Biol Sci Med Sci. 1998;53:M20-6.

8. Seidler S, Zimmermann HW, Bartneck M, Trautwein C, Tacke F. Age-dependent alterations of monocyte subsets and monocyte-related chemokine pathways in healthy adults. BMC Immunol. 2010; doi: 10.1186/1471-2172-11-30.

9. Ahmadi-Abhari S, Luben RN, Wareham NJ, Khaw KT. Distribution and determinants of C-reactive protein in the older adult population: European Prospective Investigation into Cancer-Norfolk study. Eur J Clin Invest. 2013; 43:899-911.

10. Xu H, Barnes GT, Yang Q, Tan G, Yang D, Chou CJ, et al. Chronic inflammation in fat plays a crucial role in the development of obesity-related insulin resistance. J Clin Invest. 2003;112:1821-30.

11. Candore G, Vasto S, Colonna-Romano G, Lio D, Caruso M, Rea IM, et al. Cytokine gene polymorphisms and atherosclerosis. In: Vandenbroeck K, editor. Cytokine gene polymorphisms in multifactorial conditions. Boca Raton: CRC Press; 2006. p. 363-78.

12. Wen $H$, Gris $D$, Lei $Y$, Jha $S$, Zhang L, Huang MT, et al. Fatty acid-induced NLRP3-ASC inflammasome activation interferes with insulin signaling. Nat Immunol. 2011;12:408-15.

13. Vasan RS, Sullivan LM, Roubenoff R, Dinarello CA, Harris T, Benjamin EJ, et al. Inflammatory markers and risk of heart failure in elderly subjects without 
prior myocardial infarction: the Framingham Heart Study. Circulation. 2003; 107:1486-91.

14. Payette $H$, Roubenoff $R$, Jacques PF, Dinarello CA, Wilson PW, Abad LW, et al. Insulin-like growth factor-1 and interleukin 6 predict sarcopenia in very old community-living men and women: the Framingham Heart Study. J Am Geriatr Soc. 2003:51:1237-43.

15. Bruunsgaard H, Ladelund S, Pedersen AN, Schroll M, Jørgensen T, Pedersen BK. Predicting death from tumour necrosis factor-a and interleukin-6 in 80-year-old people. Clin Exp Immunol. 2003;132:24-31.

16. Trichopoulos D, Psaltopoulou T, Orfanos P, Trichopoulou A, Boffetta P. Plasma C-reactive protein and risk of cancer: a prospective study from Greece. Cancer Epidemiol Biomarkers Prev. 2006;15:381-4.

17. Bruunsgaard $\mathrm{H}$. The clinical impact of systemic low-level inflammation in elderly populations. With special reference to cardiovascular disease, dementia and mortality. Dan Med Bull. 2006;53:285-309.

18. Tan ZS, Beiser AS, Vasan RS, Roubenoff R, Dinarello CA, Harris TB, et al. Inflammatory markers and the risk of Alzheimer disease: the Framingham Study. Neurology. 2007;68:1902-8.

19. Beyer I, Njemini R, Bautmans I, Demanet C, Bergmann P, Mets T. Inflammation-related muscle weakness and fatigue in geriatric patients. Exp Gerontol. 2012:47:52-9.

20. Collerton J, Martin-Ruiz C, Davies K, Hilkens CM, Isaacs J, Kolenda C, et al. Frailty and the role of inflammation, immunosenescence and cellular ageing in the very old: cross-sectional findings from the Newcastle $85+$ Study. Mech Ageing Dev. 2012;133:456-66.

21. Jenny NS, French B, Arnold AM, Strotmeyer ES, Cushman M, Chaves PH, et al. Long-term assessment of inflammation and healthy aging in late life: the Cardiovascular Health Study All Stars. J Gerontol A Biol Sci Med Sci. 2012;67:970-6.

22. Quaglia LA, Freitas W, Soares AA, Santos RA, Nadruz Jr W, Blaha M, et al. C-reactive protein is independently associated with coronary atherosclerosis burden among octogenarians. Aging Clin Exp Res. 2014;26:19-23.

23. Wassel CL, Barrett-Connor E, Laughlin GA. Association of circulating C-reactive protein and interleukin-6 with longevity into the 80s and 90s: The Rancho Bernardo Study. J Clin Endocrinol Metab. 2010;95:4748-55.

24. Giovannini S, Onder G, Liperoti R, Russo A, Carter C, Capoluongo E, et al. Interleukin-6, C-reactive protein, and tumor necrosis factor-a as predictors of mortality in frail, community-living elderly individuals. J Am Geriatr Soc. 2011;59:1679-85.

25. Ferrando-Martínez S, Romero-Sánchez MC, Solana R, Delgado J, de la Rosa R, Muñoz-Fernández MA, et al. Thymic function failure and C-reactive protein levels are independent predictors of all-cause mortality in healthy elderly humans. Age (Dordr). 2013;35:251-9.

26. Jylhä M, Paavilainen P, Lehtimäki T, Goebeler S, Karhunen PJ, Hervonen A, et al. Interleukin-1 receptor antagonist, interleukin-6, and C-reactive protein as predictors of mortality in nonagenarians: the vitality $90+$ study. J Gerontol A Biol Sci Med Sci. 2007;62:1016-21.

27. Alley DE, Crimmins EM, Karlamangla A, Hu P, Seeman TE. Inflammation and rate of cognitive change in high-functioning older adults. J Gerontol A Biol Sci Med Sci. 2008;63:50-5.

28. Beleigoli AM, Boersma E, Diniz Mde F, Vidigal PG, Lima-Costa MF, Ribeiro AL. C-reactive protein and B-type natriuretic peptide yield either a non-significant or a modest incremental value to traditional risk factors in predicting longterm overall mortality in older adults. PLoS One. 2013; doi: 10.1371/journal. pone.0075809

29. Matsushima J, Kawashima T, Nabeta H, Imamura Y, Watanabe I, Mizoguchi Y, et al. Association of inflammatory biomarkers with depressive symptoms and cognitive decline in a community-dwelling healthy older sample: a 3-year follow-up study. J Affect Disord. 2015:173:9-14.

30. Bledowski P, Mossakowska M, Chudek J, Grodzicki T, Milewicz A, Szybalska A, et al. Medical, psychological and socioeconomic aspects of aging in Poland: assumptions and objectives of the PolSenior project. Exp Gerontol. 2011;46: 1003-9.

31. Folstein MF, Folstein SE, McHugh PR. "Mini-mental state". A practical method for grading the cognitive state of patients for the clinician. J Psychiatr Res. 1975;12:189-98.

32. Klich-Rączka A, Piotrowicz K, Mossakowska M, Skalska A, Wizner B, Broczek K, et al. The assessment of cognitive impairment suspected of dementia in Polish elderly people: results of the population-based PolSenior Study. Exp Gerontol. 2014;57:233-42.
33. Katz S, Ford AB, Moskowitz RW, Jackson BA, Jaffe MW. Studies of illness in the aged: The index of ADL: A standardized measure of biological and psychosocial function. JAMA. 1963;185:94-9.

34. Skalska A, Wizner B, Więcek A, Zdrojewski T, Chudek J, Klich-Rączka A, et al. Reduced functionality in everyday activities of patients with self-reported heart failure hospitalization-population-based study results. Int I Cardiol. 2014;176:423-9.

35. Bowling A. Aspirations for older age in the 21st century: what is successful aging? Int J Aging Hum Dev. 2007;64:263-97.

36. Eklund CM. Proinflammatory cytokines in CRP baseline regulation. Adv Clin Chem. 2009:48:111-36.

37. Salvioli S, Monti D, Lanzarini C, Conte M, Pirazzini C, Bacalini MG, et al. Immune system, cell senescence, aging and longevity - inflamm-aging reappraised. Curr Pharm Des. 2013;19:1675-9.

38. Minciullo PL, Catalano A, Mandraffino G, Casciaro M, Crucitti A, Maltese G, et al. Inflammaging and anti-inflammaging: the role of cytokines in extreme longevity. Arch Immunol Ther Exp (Warsz). 2016;64:111-26.

39. Baylis D, Bartlett DB, Patel HP, Roberts HC. Understanding how we age: insights into inflammaging. Longev Healthspan. 2013;2:8. doi:10.1186/20462395-2-8.

40. Deelen J, Beekman M, Capri M, Franceschi C, Slagboom PE. Identifying the genomic determinants of aging and longevity in human population studies: progress and challenges. Bioessays. 2013;35:386-96.

41. Mekli K, Nazroo JY, Marshall AD, Kumari M, Pendleton N. Proinflammatory genotype is associated with the frailty phenotype in the English Longitudinal Study of Ageing. Aging Clin Exp Res. 2015 Aug 7. [Epub ahead of print] doi: 10.1007/s40520-015-0419-z.

42. Dato S, Bellizzi D, Rose G, Passarino G. The impact of nutrients on the aging rate: A complex interaction of demographic, environmental and genetic factors. Mech Ageing Dev. 2016;154:49-61.

43. Akin I, Nienaber CA. "Obesity paradox" in coronary artery disease. World J Cardiol. 2015;7:603-8.

44. Brzecka A, Ejma M. Obesity paradox in the course of cerebrovascular diseases. Adv Clin Exp Med. 2015;24:379-83.

45. Kim NH, Lee J, Kim TJ, Kim NH, Choi KM, Baik SH, et al. Body Mass Index and Mortality in the General Population and in Subjects with Chronic Disease in Korea: A Nationwide Cohort Study (2002-2010). PLoS One. 2015; doi: 10. 1371/journal.pone.0139924

46. Costanzo P, Cleland JG, Pellicori P, Clark AL, Hepburn D, Kilpatrick ES, et al. The obesity paradox in type 2 diabetes mellitus: relationship of body mass index to prognosis: a cohort study. Ann Intern Med. 2015;162:610-8.

47. Laird E, McNulty H, Ward M, Hoey L, McSorley E, Wallace JM, et al. Vitamin D deficiency is associated with inflammation in older Irish adults. J Clin Endocrinol Metab. 2014;99:1807-15.

48. Wood AD, Strachan AA, Thies F, Aucott LS, Reid DM, Hardcastle AC, et al. Patterns of dietary intake and serum carotenoid and tocopherol status are associated with biomarkers of chronic low-grade systemic inflammation and cardiovascular risk. Br J Nutr. 2014;112:1341-52.

49. Oe Y, Mochizuki K, Miyauchi R, Misaki Y, Kasezawa N, Tohyama K, et al. Plasma TNF-a is associated with inflammation and nutrition status in community-dwelling Japanese elderly. J Nutr Sci Vitaminol. 2015;61:263-9.

50. Lehtimäki T, Ojala P, Rontu R, Goebeler S, Karhunen PJ, Jylhä M, et al. Interleukin-6 modulates plasma cholesterol and C-reactive protein concentrations in nonagenarians. J Am Geriatr Soc. 2005;53:1552-8.

51. Cesari M, Onder G, Zamboni V, Capoluongo E, Russo A, Bernabei R, et al. $\mathrm{C}$-reactive protein and lipid parameters in older persons aged 80 years and older. J Nutr Health Aging. 2009;13:587-93.

52. Ferrara A, Barrett-Connor E, Shan J. Total, LDL, and HDL cholesterol decrease with age in older men and women. The Rancho Bernardo Study 1984-1994. Circulation. 1997;96:37-43.

53. Olszanecka-Glinianowicz M, Chudek J, Szromek A, Zahorska-Markiewicz B. Changes of systemic microinflammation after weight loss and regain - a five-year follow up study. Endokrynol Pol. 2012;63:432-8.

54. Dahlén EM, Tengblad A, Länne T, Clinchy B, Ernerudh J, Nystrom FH, et al. Abdominal obesity and low-grade systemic inflammation as markers of subclinical organ damage in type 2 diabetes. Diabetes Metab. 2014;40:76-81.

55. Valentine RJ, Vieira VJ, Woods JA, Evans EM. Stronger relationship between central adiposity and C-reactive protein in older women than men. Menopause. 2009:16:84-9. 
56. Beavers KM, Beavers DP, Newman JJ, Anderson AM, Loeser Jr RF, Nicklas BJ, et al. Effects of total and regional fat loss on plasma CRP and IL-6 in overweight and obese, older adults with knee osteoarthritis. Osteoarthritis Cartilage. 2015;23:249-56.

57. Varadhan R, Yao W, Matteini A, Beamer BA, Xue QL, Yang H, et al. Simple biologically informed inflammatory index of two serum cytokines predicts 10 year all-cause mortality in older adults. J Gerontol A Biol Sci Med Sci. 2014;69:165-73.

58. Vaucher J, Marques-Vidal P, Waeber G, Vollenweider P. Cytokines and hs-CRP levels in individuals treated with low-dose aspirin for cardiovascular prevention: a population-based study (CoLaus Study). Cytokine. 2014;66:95-100.

Submit your next manuscript to BioMed Central and we will help you at every step:

- We accept pre-submission inquiries

- Our selector tool helps you to find the most relevant journal

- We provide round the clock customer support

- Convenient online submission

- Thorough peer review

- Inclusion in PubMed and all major indexing services

- Maximum visibility for your research

Submit your manuscript at www.biomedcentral.com/submit
Biomed Central 